In Focus

\title{
The Resilience of Small Television Markets to COVID-19: the Case of Lockdown
}

$\$$ sciendo 


\section{ABSTRACT}

This article presents a case study of Lockdown, an anthology series developed by two production companies under strict COVID restrictions in Flanders, centred on a prison visiting space. Every episode is written and directed by different screenwriters and directors. The case study clearly shows how a combination of creativity of Flemish independent producers, a felt need to counter the damaging effects of COVID on Flemish audio-visual industries, and the need to produce under strict hygienic and social distancing rules, resulted in a unique creative concept, that, ironically, might not have been achievable under normal circumstances. The analysis shows that the smallness of the Flemish market, which over the past decades resulted in an industry dynamism characterized by improvisation, voluntarism, high dependency on collaboration and short term financial planning, is precisely what might have provided the ideal backdrop for the production of this unique series.

\section{INTRODUCTION}

COVID-19 has hit the audio-visual industry hard: private broadcasters' advertisement revenues have dropped, tax incentives income for audio-visual industries have plummeted, producers have received fewer commissions and, most importantly, various ongoing projects have been temporarily stalled, leaving thousands of freelancers and dozens of SME's unable to persevere. The crisis has reinforced an already fragile industry, especially in small markets, and has added difficulties on top of the already precarious conditions in which a lot of creative professionals find themselves working (e.g. lacking social protection, dependent upon a limited number of players).

While governments in European markets are struggling to arrange short-term support for the arts (which has already suffered cutbacks in multiple countries) and creative industries, producers, screen agencies and broadcasters, from their vantage point, have been looking for creative solutions to respond to the impact of COVID-19. Amongst these responses are the growing number of web series that have put the pandemic at the core of their stories and made social distancing requirements part of the production set-up. Australian director Luke Eve launched a web series Cancelled, that "authentically portrays both the tragedy and unexpected comedy of living in pandemic times" (Reich 2020). Months earlier, Netflix announced Social Distance, a new anthology series by the Orange is the New Black creator Jenji Kohan, depicting the absurdity of social conventions in what has started to be called the 'new normal' (Goldberg 2020). Additionally, on June 10, the first ever video- conferencing-based series Staged premiered on BBC iPlayer, 
with David Tennant and Michael Sheen playing themselves as they rehearse online for a West End production that has been postponed due to COVID-19 (Mangan 2020).

However, it is not only the larger markets which have been showing resilience and have been launching creative solutions to keep producing content. In Flanders (i.e. the Dutch speaking-part of Belgium), production companies and broadcasters devised a batch of new productions that specifically place the lockdown as a starting point. The Belgian version of SKAM, WTFock, continued as WTFockdown, with the actors filming themselves with mobile phones and webcams; youth channel Ketnet and Eyeworks launched Ik U Ook and VTM announced the upcoming web series Brak.

This article presents the case study of a fourth project, Lockdown, an anthology series taking place in a prison visiting space, with every episode directed and written by different screenwriters and director. The article adopts a production studies perspective, which requires examining the full context in which media products are created and are affecting production cultures (Caldwell, 2008; Banks, 2014). After briefly contextualizing the Flemish market, the case study of Lockdown will be presented, building on expert interviews with producers, screenwriters and directors. These interviews were conducted between August $4^{\text {th }}$ and September $10^{\text {th }}$ 2020. The article demonstrates how the combination of audio-visual funds, screen agencies and the public broadcaster but mostly producers and creative talents have provided the breathing space for audio-visual professionals to produce in the short-term and paved the way for innovating storytelling in small markets in the long run.

What makes this series stand out from similar short-format productions developed during COVID-19 is the fact that

Kaat Beels (director), Wouter Bouvijn (director, writer), Gilles Coulier (director, producer, ceator), Remco Hoste (line producer), Guy Goedzelschap (producer), Jan Pepermans (writer), Stephanie Vanhecke (writer). in this case, a real-life 'lockdown' has not only resulted in having to deal with social distancing (which is the premise of a lot of similar experiments taking the lockdown as their starting point) but has also helped in shaping the concept of the show (a prison visiting space) and the type of narration (short films), while simultaneously contributing to the development of a project that given the large pack of (increasingly international) talents involved, the unique collaboration and the short-term deadlines would not have been possible in Flanders.

\section{FLANDERS, A VIBRANT YET FRAGILE PRODUCTION INDUSTRY}

The Flemish television market portrays the characteristics of a small market, (i.e. a limited number of players and a limited domestic market of 6 million inhabitants), which constrict both ad-revenue, and SVOD and TVOD revenues. Smaller budgets generally are a consequence of smaller markets, which in turn (theoretically) will limit the export potential of television productions (Raats, Jensen 2020; Picard 2011; Puppis 2009). Despite these structural limitations, the Flemish television production industry is characterized by a significant volume of domestic productions, boosted by fierce competition among three broadcasters including the public broadcaster VRT and its commercial counterparts DPG and SBS). Scripted television takes a significant role in the programming slots of these broadcasters, resulting in a mix of soap series, high end drama [usually on Sunday evening slots], mid-week 'dramedies' and children's television fiction. In 2019, no fewer than 23 original series debuted or presented new seasons (high-end drama, children's fiction, sitcom, soaps, web series) (Raats 2020).

The key players in the scripted television market in Flanders are production companies. Independent television production in Flanders is highly scattered, with more than 60 companies producing domestic content of various genres, and more than 10 companies regularly producing scripted television. Most of the 
scripted content is usually commissioned by broadcasters externally. Producers approach broadcasters with story concepts, the former then apply for funding from the Flanders Audiovisual Fund and secure third-party funding through the Belgian tax shelter incentive. Increasingly, television distributors are co-financing fiction as a strategy to attract new customers to their pay-tv offerings and as a means to differentiate themselves from global SVOD players through local content.

Following the expansion of distribution outlets and the success of the Nordic Noir that has increased the appetite for foreign language drama globally, Flemish series have been increasingly picked up for international export (Raats, lordache 2020). The uptake in exports has also led to the growing importance of global distributors and broadcasters as co-producers/ co-financiers, thus enhancing the productions' scale and scope and largely following the much acclaimed Scandi-model.

(Jensen et al. 2016).

Despite its vibrant activity, following the impact of global streaming platforms, the Flemish television industry is characterized by its fragility with producers continuously experiencing increased pressure on production budgets, creative talent and industry workers expressing higher demands on salaries and working conditions, and screen agencies and broadcasters lobbying for increasing government grants to be able to preserve the Flemish 'unique ecosystem.' It is this exact environment of flexibility and agility by the Flemish production industry, as well as the need to continue functioning to stay alive, in which the creation of Lockdown should be understood.

\section{PRODUCING LOCKDOWN}

All the while that the Flemish audio-visual industry was being heavily hit by the COVID19 crisis and productions were either postponed or cancelled, Lockdown appeared as a project that would prove the resilience of Flemish producers in times of an actual lockdown. The show's premise and setup are entirely intertwined with its core objectives; that is, being able to produce a unique and high-quality project in safe conditions at a time when most other productions were stalled.

The project was conceived by two production companies, De Wereldvrede, specializing in scripted high-end drama (feature film and series), and Lecter Media, specializing in reality and human-interest formats and also increasingly active in the Dutch market. Maarten Moerkerke (director of a.o. Thieves of the Woods) and Gilles Coulier (director of a.o. The Day and War of the Worlds, and head of the Flemish Director's Guild) - having experience in collaborative production and joint decision-making processes - proposed the idea and both served as showrunners. The decision to co-produce resulted from pragmatism and efficiency. First, both creators knew each other well and, second, the collaboration also showcased the project as a unique industry partnership; a coalition that has been repeatedly mentioned in pitches, press releases and funding applications with the Flanders Audiovisual Fund (respondents 1, 2, 3). Both production companies shared efforts and format rights. Aside from the budget being significantly lower than the usual budgets allocated for high-end drama (approximately 5-7 million euros per series), the composition of the budget resembled approximately that of larger projects (see e.g. Raats et al. 2016; Raats, Jensen 2020). The show's budget consisted of broadcasting financing, a 200,000 euro grant from the Flanders Audiovisual Fund, tax shelter financing ${ }^{2}$ and support from the collective rights agency SABAM.

Quite early in the brainstorming sessions, both creators conceived the concept of an anthology series taking place inside a penitentiary facility's visiting room. The title 'Lockdown' serves a double meaning; pointing to the circumstances in which the project was developed and also referring

The federal tax shelter system provides a fiscal advantage for third-party investors in the production of audiovisual content. The total amount eligible for tax sheltering is dependent on the total budget of productions. 
to the surroundings in which the show took place.

Having two people facing each other, separated by the glass partition from the visiting room, not only provided the perfect conditions to shoot safely, but "it [became] a metaphor for the situation people currently find themselves in" (respondent 2). Since its inception, it was decided to conceive Lockdown as an anthology series. Inspired by examples such as Room 104 (HBO) - each time telling a story taking place in the exact same motel room - the creators wanted to tell different stories, covering different genres and developed by different directors, with each director telling their story within the same confines of the setting and the format $(12 \times 10$ minute episodes). The creators then developed a shortlist of directors and screenwriters to invite. "That really was the most difficult part of the process. Because there are simply so many talented people you want to work with. Plus: you want a mix of talents to make sure the short films differ enough from each other." (Respondent 1). A combination of well-established, as well as young and upcoming talent, was pursued along with a mix of directors mostly working on scripted television or, most usually, on feature film projects. Additionally, the producers pursued a balance in gender/diversity. This was encouraged by the Flanders Audiovisual Fund, which backed up the project financially with support from its web series innovation grants funding.

The project was pitched to the Flemish public broadcaster VRT. "For us it was a logic choice that 'één' (the first generalist channel of VRT) would be the partner to present this to" (Respondent 1). The unique character of the show and the fact that established names were already attached to the project (including internationally acclaimed Belgian actors Veerle Baetens and Mathias Schoenaerts, Academy Award nominee Michael Roskam, local 'legend' writer/director Jan Eelen or the Flemish bestseller novelist Dimitri Verhulst) made this a very appealing and easy pitch for the broadcaster. Despite the short format and opportunities to showcase the project on the public broadcasters' online portal, VRT chose to air 3 episodes back-to-back on four consecutive evenings in its prime-time slot on the first channel. What partially explains this decision is that it allows VRT commissioners to invest larger sums in the production, given the high audience potential on linear television. VRT included Lockdown as one of 4 'Corona-proof' series commissioned by the broadcaster. VRT gave full editorial freedom to the makers in developing their stories. The only precondition was that the stories could not deal with the COVID-19 crisis itself, which was also the wish of the creators.

The anthology set-up also provided the best circumstances in which to work. For example, directors brought in their own screenwriter, actors, director of photography and composer. Other production units remained the same throughout the duration of the shoot (production office and accounts, make-up and costumes, sound, etc.). This set-up allowed the producers to contact and book crews on short notice since each director, actor and DOP only needed to be on set for two days. That each team developed their own projects alongside each other also saved a significant amount of time during the pre-production and post-production processes. Most important of all, it created small work groups which would limit potential damage to the production in the event of any of the crew members tested positive for COVID-19.

\section{DEVELOPING LOCKDOWN}

Directors provided a baseline of their project to the showrunners, which was then collected and discussed by the creators. Some directors penned down their own story, while others worked with screenwriters. In all cases, projects were conceived as a close collaboration. Surprisingly, most projects showed a great diversity in topics, tone and genre (Respondents 1 \& 3). Each writer clearly felt the need to take the basic concept of a prison's visiting room and develop out-of-the box ideas. 
The image of the "typical father-son talk," often popped up during interviews as ideas the makers actually wanted to shy away from. Having to work within specific confines was seen more as a fascinating challenge rather than a hurdle since "it steers your thinking, which is necessary if you have to come up with an idea in such a short notice, but at the same it still allows you to go wild, push to see what's possible with that arena and premise." (respondent 7).

Some of the directors went quite far 'out-of-the-box,' proposing daring ideas such as one of the films revolving around a doppelgänger (which put time pressure on production as the actress had to play both roles). Another film was shot in black and white, yet another made heavy use of special effects and another of the projects simply had no actors at all. "It's remarkable how different the same setting can look, just by how you colour it, how you photograph it, and how you pace your story." (Respondent 3).

For some of the interviewees, the fact that they were not made aware of each other's projects, served as a trigger to perform better because "you're curious about what others have done, you work with these established names, then you don't want to lag behind" (respondent 2). The curiosity for each other's projects was shared amongst interviewees, yet, most did not wish to contact other directors/screenwriters to discuss ideas or share experiences. Leaving competition aside, most directors welcomed criticism and feedback from the producers and all of them shared the mantra of striving towards a common goal rather than just being "the sum of its parts."

The interviewees stated that this project was created more as a collection of short films rather than a television series, let alone as a 'short format television show' or 'web series.' The setting and tone, the attention to cinematography, the broad instead of niche genre and the appeal to young audiences, were elements that made Lockdown distinctive from the increasing slate of short format series. Respondents talked about their projects as 'short films,' having to prove their own quality. The idea that each film could also be watched as a stand-alone or that it could even be submitted to film festival selections, was also how the creators pitched the project to the directors involved. One director referred to the whole "guerrilla way of working" as a reminder of her days back in college and of the beginning of her career when she was making short films, with a similar enthusiasm and a constant need to find creative solutions to circumvent budget constraints (respondent 4).

\section{SHOOTING LOCKDOWN}

And a guerrilla way of working it was - a short, speedy process of four months in which the production evolved from an idea, to being green-lit by the audio-visual fund and broadcaster, to going into actual production. Two and a half weeks were allocated to each screenwriter to pen down the script from the moment the concept was approved by the producers. Only two days per film were allocated - one day for rehearsing and one for shooting. As all directors wished to make use of the entirety of the allocated time on set, everyone wanted to be certain that sufficient shots were filmed in order to tell their story as returning the next day was not possible. The result was heavy and long shooting days. Would they have done it differently if they had the opportunity to start over? "Two shooting days would have been likely better than one." (respondent 4)

At the time of writing, audio-visual production has slowly restarted in Belgium. Interviewees acknowledged the impact of COVID-19 on sets, requiring additional costs up front but ultimately slowing the pace of shoots, thus requiring additional shooting days (respondent $1 \& 4$ ). For Lockdown, which was created to be entirely 'Corona-proof' before the protocol was agreed upon, the impact was fairly limited. Requiring a limited cast of only two actors facing each other and separated by a glass partition, avoided the biggest difficulty of filming intimate scenes under social distancing rules. The rest was fairly standard practice necessitating face masks, social 
distancing, continuous disinfection of sets, separate catering, and loads of alcohol gel everywhere (respondent 4). Luckily nobody in the crew tested positive throughout production.

At the time of writing, the different Lockdown films have been in postproduction with some of the short films having already been edited, resulting in the crews' and producers' enthusiasm and satisfaction. Additionally, the format of Lockdown provides an accessible and attractive format for the international market. Whereas talks had already started about potential sales, no deals have been secured yet; however, the producers showed enthusiasm about the potential saying "this is something that could ideally be transposed in various contexts and countries. It also offers many inroads for new seasons. We feel we have something special here" (Respondent 2).

\section{CONCLUSIONS}

Lockdown is exemplary for a growing number of projects that divert from traditional formats of scripted drama that follow the requirements of linear television. The rise of global SVODs, enabling binge-watching and avoiding strict scheduling requirements, the various new outlets and the multi-platform use of media audiences (especially by younger generations) will likely result in a widespread creation of such formats. The relatively low budgets, combined with the need for players in the market to expand catalogues with as many titles as possible in an increasingly competitive market, could be the catalyst. For some markets, including Flanders, COVID-19 is a catalyst on its own. This has been the case with Lockdown, a series created and inspired by its eponymous title, yet a series that does not want to be tied to the short format genre, but rather, a unique collection of short films presenting the diverse talent of Flanders' production pool.

From the interviews, it has been clear that the uniqueness of the project has been the result of a combination of 'perfect conditions.' From a global pandemic allowing many talented crews to block schedules to production partners readily acknowledging the project's value, to a government lockdown (although repeatedly dismissed as not being 'a real lockdown' by government officials), all factors contributed to the perfect title/format and potential commercial success. The restrictions presenting themselves beforehand - What if the director tests positive? How can we bring actors in the same frame without risks? How do we write, develop, cast and shoot in such a limited timeframe? - were turned into advantages and helped shape the unique character of the series.

At the same time, the 'unique' character implies that repetition of the circumstances is less likely to take place. Availability was high, budgets were low, and all involved shared an enthusiasm and perceived need to make this production work. To this end, directors even gave up their fee to invest it in the production and both production companies also acknowledged that profit margins were practically non-existent. In that regard, Lockdown can be viewed as exemplary as a "low-budget, high creativity" product which characterizes audio-visual production in Flanders following from two decades of remarkable professionalisation. The production confines and the enormous flexibility and creativity found within those confines, are almost metaphorical for the Flemish drama production. Analysis shows that it is precisely the smallness of the Flemish market which over the past decades has contributed to the creation of a dynamic industry characterized by improvisation, voluntarism, high dependency on collaboration and shortterm financial planning - which might have provided the ideal backdrop for the production of this unique series.

Finally, the case study has also shown the resilience of the Flemish television industries to linear programming schedules as the public broadcaster explicitly wanted to schedule the series in prime time, which would thus allow the programming managers to allocate more funding. Underlying this logic is a lack of risk-taking within 
Public Service Media to devote significant funding to online-only content, although this would result in significantly lower viewing numbers. And thus, ironically, while Lockdown was created as a rapid response with significant flexibility in terms of creating, planning, and shooting; the high quality and unique crew resulted in the series being moved to the beginning of January 2021, as the short films will be released first in cinema during the 2021 Ostend Film Festival. Notwithstanding the emphasis on linear broadcasting, Lockdown is likely to further pave the way for more experimental short format content in Flanders.

\section{REFERENCES}

Banks, Miranda J. 2014. 'How to study makers and making'. In: Manuel Alvardo, Milly Buonanno, Herman Gray; Toby Miller (eds) The SAGE Handbook of Television Studies. London: Sage, 117-132.

Caldwell, John T. 2008. Production Culture. Industrial Reflexivity and Critical Practice in Film and Television. London: Duke University Press.

Goldberg, Lesley. 2020. JJenji Kohan Sets 'Social Distance' Anthology Series at Netflix'. Url: https://www.hollywoodreporter.com/live-feed/jenjikohan-sets-social-distance-anthology-series-atnetflix-1292270.

Jensen, Pia Majbritt; Nielsen, Jakob; Waade, Anne Marit. 2016. 'When public service drama travels: The internationalization of Danish television drama and the associated production funding models.' The Journal of Popular Television, 4, 1, 91-108.

Mangan, Lucy. 2020. 'Staged review - Michael Sheen and David Tennant get meta. In: the Guardian' (online). Url: https://www.theguardian.com/tv-and-radio/2020/ jun/10/staged-review-michael-sheen-david-tennnantthe-trip-the-ego (17.08.20).

Picard Robert. 2011. 'Broadcast Economics, Challenges of Scale, and Country Size.' Gregory Ferell Lowe, Christian S. Nissen. (eds), Small among Giants: Television Broadcasting in Smaller Countries. Göteborg: Nordicom, 43-56.

Puppis, Manuel. 2009. 'Media Regulation in Small States.' International Communication Gazette, 71, 1-2. Reich, Hannah. 2020. 'Coronavirus lockdown series 'Canceled' captures pandemic living in all its comedy and anxiety.' In: $A B C$ News (online). Url: https://www.abc. net.au/news/2020-08-07/coronavirus-lockdown-webseries-cancelled-drama-comedy-pandemic/12525688 (17.08.20).

Raats, Tim. 2020. 'The war of the platforms en wat het betekent voor de Vlaamse audiovisuele sector' [The war of the platforms and what it means for the Flemish audio-visual sector]. Presentation given for the Flemish Screenwriters Guild (Scenaristengilde), 16 September 2020.

Raats, Tim, Jensen, Pia Majbritt. 2020. 'The role of public service media in sustaining TV drama', Television and New Media, online first. 